\title{
From the Five Aggregates to Phenomenal Consciousness: Toward a Cross-Cultural Cognitive Science
}

\author{
Jake H. Davis and Evan Thompson
}

Buddhism originated and developed in an Indian cultural context that featured many first-person practices for producing and exploring states of consciousness through the systematic training of attention. In contrast, the dominant methods of investigating the mind in cognitive science have emphasized third-person observation of the brain and behavior. In this chapter, we explore how these two different projects might prove mutually beneficial, in particular for investigating the relationship between attention and consciousness. We ask not only what Buddhism can do for scientists but also what science can do for Buddhists. How might Buddhist theory and practice be useful to cognitive scientists working to understand the mind? And how might cognitive science help Buddhists to deepen their understanding of their own tradition?

In a ground-breaking article on meditation and the neuroscience of consciousness, neuroscientists Antoine Lutz and Richard Davidson, together with Buddhist scholar John Dunne, stress that in order to investigate properly a given type of meditation practice, scientists must take account of the traditional theoretical frameworks used to conceptualize and teach that practice (Lutz, Dunne, and Davidson 2007). We follow their lead and focus here on both traditional formulations and recent scientific investigations of "mindfulness" meditation. In this form of practice, meditators aim to cultivate a lucid awareness of their moment-to-moment bodily, emotional, perceptual, and cognitive processes. For this reason, mindfulness meditation may be especially relevant to contemporary scientific and philosophical debates about the nature of attention and its relationship to consciousness. Moreover, because of the widespread application of mindfulness meditation in secular settings such as healthcare, this form of practice is already the subject of a burgeoning field of investigation within psychology and neuroscience.

Mindfulness meditation is formulated in the early dialogues containing the Buddha's teachings, as preserved in the Chinese, Sanskrit, and Pāli texts of 
the various East and South Asian Buddhist traditions. Yet it is teachers from Theravāda Buddhist countries such as Sri Lanka, Thailand, and Burma who, drawing from the Pāli texts, have most explicitly emphasized mindfulness practice. For this reason and for the sake of simplicity, we make reference especially to Pāli textual sources and terminology in this chapter. Nevertheless, it should be borne in mind that similar practices are found in other Buddhist traditions, especially Tibetan and Chan/Zen traditions.

Situating Buddhist views within recent scientific debates about consciousness allows us to see how these views might be tested experimentally and thereby opens up new understandings of what these ancient teachings mean for us today. At the same time, understanding the conceptual frameworks of the Buddhist teachings can help scientists to refine the theoretical frameworks they bring to scientific research on meditation and consciousness. This opportunity is lost if we simply apply existing scientific frameworks to interpret data from experiments on meditation practices.

A case in point is the issue of how to conceptualize "mindfulness" in a way that can bridge between Buddhist theory and cognitive science, and we address this issue first. We continue this cross-cultural project by exploring how to bring the theoretical frameworks of cognitive science into conversation with one traditional and foundational Buddhist model of the mind. We then discuss several ways in which recent studies of meditation may shed new light on the relationship between attention and consciousness. Reciprocally, understanding these experimental results in the light of Buddhist theory may suggest new avenues for scientific research. Finally, we point to one such area for future investigation, the central question of how the particular forms of attention training involved in mindfulness meditation might alter and attenuate habitual emotional reactions.

\section{The Meaning of Mindfulness}

Buddhist teachings include many methods for training practitioners' habits of mind. The strong emphasis on moral conduct, for example, can be seen as a means for protecting oneself from unwholesome mental states (greed, hatred, and delusion). Cognitive science has yet to study ethical training and its mental effects, so investigations of dedicated practitioners of Buddhist monastic vows - from a social neuroscience perspective, for example - might prove fruitful. Many Buddhist techniques of reflection, such as reflection on the inevitability of death (maranasati), act as a complement to ethical training. This general type of reflective intervention, however, has been popular in modern forms of cognitive therapy, so scientific investigations may have less to learn from the investigation of specifically Buddhist methods of reflection than from other types of Buddhist mental practices. 
The term "meditation" is generally used to refer to a third category of practices involving attention training techniques aimed at directly cultivating particular positive mental states. These practices range from cultivating states such as loving-kindness, or literally friendliness (mettā), to practices aimed simply at cultivating a settled and unified state of mind (samādhi) through concentration on a visualized image of a colored disk or a light. In these forms of meditation, practitioners counteract mind-wandering by repeatedly bringing the mind back to the subject of meditation. The use of such methods of attention training for developing altered states of consciousness through strong concentration was widespread at the time of the Buddha. Buddhist texts relate how before his enlightenment the Buddha studied techniques for concentrating the mind under teachers such as Ālāra Kālāma and Uddaka Rāmaputta (MN.36). Yet these early Buddhist texts also emphasize that the method of mind training that the Buddha went on to discover for himself was novel, with results that differ importantly from those that were being taught by his contemporaries. Of the many types of mental cultivation employed in various cultural contexts, we focus here on the Theravāda Buddhist practice of mindfulness meditation.

The Theravāda practice of mindfulness meditation can be broadly characterized by the aim to cultivate attention to one's own present experience. Because this practice includes returning the mind again and again to present-moment experience, mindfulness meditation includes an element of concentration, though different teachers emphasize this concentrative aspect to differing degrees. In other concentrative practices, one might return the attention again and again to a particular feeling of friendliness, or a particular mental image of color or light, thereby cultivating the continuity and stability of a particular object in the mind. In contrast, mindfulness practice aims to develop a settled type of attention on objects that are constantly changing. Present experiences of heat or cool in the body, of anger or of joy, of concentration or of distractedness, constantly arise and pass away again. Indeed, Buddhist teachings claim that experiencing for oneself in this direct and focused way the impermanent and unstable nature of all aspects of experience brings about a profound change in how one relates to oneself and others.

The majority of psychological and neuroscientific studies of mindfulness meditation to date have been based on data from participants in the Mindfulness-Based Stress Reduction (MBSR) program. This eight-week program was pioneered by Jon Kabat-Zinn at the University of Massachusetts Medical School in Worcester, Massachusetts in 1986. The program has been replicated and adapted widely and is now offered in the secular context of hospitals and clinics around the world. Studies comparing participants in the MBSR program with control groups have shown mindfulness practice to correlate with significant reductions in suffering associated with various illnesses (e.g. Grossman et al. 2007). Mindfulness-Based Stress Reduction has also been 
associated with structural changes in the brain (changes to gray matter concentration or the density of cell nuclei) (Hölzel et al. 2011a; for a review see e.g. Hölzel et al. 2011b).

To study the effects of such therapeutic interventions on the brain and the rest of the body, scientists need to employ conceptual constructs of the phenomenon under investigation that guide where and how they look. Thus, in studying the health benefits and neural mechanisms of mindfulness meditation, scientists have had to ask what precisely mindfulness is (Davidson 2010). As Kabat-Zinn notes in a recent article, he used the term "mindfulness" in his presentations "as a place-holder for the entire dharma," that is, as an umbrella term meant to point in a secular, accessible way toward the many varied techniques employed in a diverse array of Buddhist traditions (Kabat-Zinn 2011, 290). Kabat-Zinn had been influenced by Korean Zen Buddhist teachings as well as by formulations of mindfulness meditation by Theravāda Buddhist teachers, who draw more explicitly on texts from the Pāli discourses such as the Mahāsatipațthāna Sutta or "Longer Discourse on Mindfulness" (DN.22). But many of those trained to teach MBSR to patients, as well as the scientists studying such interventions, have had little or no direct contact with the Buddhist traditions from which the mindfulness technique is derived. As a result, attempts in the scientific literature to formulate what mindfulness is have often proceeded in almost total independence from theoretical formulations of mindfulness practice contained in Buddhist textual traditions. In the absence of references to such traditional canonical sources, there has been an inordinate focus on one particular phrase Kabat-Zinn used in his seminal introductory guide for practitioners to describe mindfulness, namely, "paying attention in a particular way: on purpose, in the present moment, and nonjudgmentally" (Kabat-Zinn 2004, 4). Thus Bishop and colleagues, in proposing an operational definition of mindfulness for clinical psychology, summarize the literature by noting that "mindfulness has been described as a kind of nonelaborative, nonjudgmental, present-centered awareness in which each thought, feeling, or sensation that arises in the attentional field is acknowledged and accepted as it is" (Bishop et al. 2004, 232).

When specific references do occur in the scientific literature to the Buddhist textual sources, these references often consist in noting that the term "mindfulness" is a translation of the Pāli term sati. In Buddhist theory, however, the term sati carries connotations of memory and remembrance, making attempts to understand mindfulness as a present-centered, nonelaborative, and nonjudgmental attention appear inaccurate and confused (Bodhi 2011; Dreyfus 2011). Indeed, the term "mindfulness" seems to have been chosen by early translators of the Pāli texts because they saw parallels not with a notion of nonjudgmental present-centered attention, but rather between the Christian ethical notion of conscience and the textual usage of sati in the context of holding in mind and being inspired by certain truths, for the sake of improvement 
of one's ethical character (Gethin 2011). The broad usage of the term sati is perhaps best captured by the colloquial English notion of "minding." The Pāli texts employ sati in reference to everything from "minding" one's livestock (MN.19) to "minding" one's meditation object in practices such as loving-kindness (Sn.115), in addition to using sati specifically in the context of mindfulness meditation or, more literally, in the establishment of sati (sati-upatthāna). ${ }^{1}$ As one prominent translator of the Pāli texts notes, in the traditional formulation of mindfulness meditation in Mahāsatipațthāna Sutta, sati is only one of a number of factors present (Bodhi 2011). The role of sati in minding or being attentive to the object of meditation is thus claimed to be separate from and complementary to a number of other factors. A meditator engaged in mindfulness meditation is described as dwelling watching the object of meditation (anupassi viharati), with ardent effort ( $\bar{a} t \bar{a} p \bar{i})$, clear awareness (sampajāno), as well as attentiveness $(\operatorname{satim} \bar{a})$, and in this way removing desire and discontent in regard to the world (vineyya loke abhijjhā-domanassam).

Careful understanding of the textual sources in the context of recent scientific research can suggest a way forward for psychological conceptualizations of mindfulness meditation, and thereby for scientific investigations employing these theoretical constructs. In its general sense of "minding" something, sati clearly can involve elaborative and evaluative cognitive processes. In the role sati plays in the context of mindfulness meditation, however, the involvement of memory may be of a more limited and specific kind. Thus Dreyfus (2011), in a discussion based on Pāli texts as well as Indian Mahāyāna Abhidharma sources, argues that sati consists in "retentive focus," the ability of the mind to hold its object and not float away from it, a conception close to the cognitive psychology construct of working memory (see later). Like Dreyfus, we believe that the technical vocabularies used in cognitive science can provide a greater degree of precision for characterizing mindfulness than can the operational definition of mindfulness in clinical psychology (notwithstanding the usefulness that definition may have for therapeutic purposes). Moreover, the cognitive science vocabulary can help to capture the care and precision with which the Buddhist terms are used in their native philosophical context.

Consider how selective attention is currently conceptualized in cognitive science. Two types of attention, which rely on distinct neural systems but also share a common neural network, have been distinguished by cognitive neuroscientists (Corbetta and Shulman 2002). If we ask you to switch your attention from the words on this page to the sensations in your right hand, and you comply, you are employing so-called top-down, endogenous orienting. Scientists distinguish this voluntary form of attention from so-called bottom-up, stimulus-driven attention, which is activated when a strong or salient stimulus, such as a loud siren or a flash of light, grabs your attention. Top-down attention depends on generating and maintaining a "control set" that specifies in advance what you are to select; thus, when you switched your attention to the sensations in your 
right hand, you did so by forming an attentional control set on the basis of our instructions. The maintenance of an attentional control set depends crucially on working memory, the ability to retain task-relevant information on a short-term basis. Working memory has been shown to play an important role in visual selective attention (De Fockert et al. 2001) and seems to play a similar role in directing bodily awareness. In a paradigm developed by Ruth Schubert and colleagues, subjects are instructed to attend either to the left or right hand, while tactile stimulation is applied to left and right index fingers with the mechanical pins of a Braille stimulator (Schubert et al. 2006, 2008, 2009). In a series of studies integrating behavioral tasks with multiple neuroimaging methods, Schubert and colleagues found evidence that selective, top-down spatial attention, for instance to the left hand, functions to increase subjects' ability to detect and report on weak stimuli by directly amplifying early sensory responses to stimuli in this area of the body and inhibiting responses to other areas. Desimone and Duncan's (1995) well-known "biased-competition" model of attention makes sense of such results by suggesting that representations in early sensory areas compete with one another for access to downstream resources, such as those involved in the ability to have conscious access to the sensory response and to report on it, while top-down modulation by attentional control sets serves to bias these competitions in favor of certain sensory responses. In a more recent proposal, Rolls $(2007,442)$ draws on the biasedcompetition model to suggest that attention is an emergent process, in which feedback and feedforward effects between working memory areas and sensory processing areas settle into an optimal configuration for energy minimization. In this light we may hypothesize that when meditators apply instructions to attend to the sensations of the breath in mindfulness practice, working memory plays a role in specifying how attention is to be directed. This suggestion is consistent with results showing that, following a course in the MBSR program, participants show increased performance on tasks measuring such top-down orienting (Jha, Krompinger, and Baime 2007), as well as enhanced activity in brain areas specific to interoceptive attention (Farb, Segal, and Anderson 2013a, 2013b).

In the canonical formulation of satipatthāna or "establishing sati" (DN.22; MN.10), meditators are instructed to pay attention to every aspect of daily life; in going, for instance, the ardent meditator knows "I am going." Likewise, one influential form of mindfulness practice descended from the Mahasi Sayadaw of Burma and popularized by American teachers such as Joseph Goldstein and Sharon Salzberg employs mental noting: at introductory stages of practice, meditators are instructed to use mental labels to note everything from the movement of the breath to perceptual processes such as seeing and hearing, and even mental states such as boredom, interest, restlessness, or joy. Such minimal conceptual labels might seem insufficient for developing the penetrative understanding, pañ $\tilde{n} \bar{a}$, that mindfulness is said to bring. In light of the 
cognitive science of attention reviewed above, however, we can understand meditators' use of labels such as "I am going" not as a phenomenological analysis of experience, nor as a metaphysical analysis of the nature of reality, but rather as holding in working memory a mental representation that functions to direct top-down attention in ways that can have transformative effects.

\section{A Buddhist Model of the Mind}

The five aggregate model of the mind, found across many Buddhist philosophical traditions, parallels a number of distinctions drawn in cognitive science (Varela, Thompson, and Rosch 1991). In the Pāli texts these five aggregates (khandas) are listed as rūpa, vedanā, sañ $\tilde{n} \bar{a}$, samkhära, and viññāna. It would be nice if we could simply list what each of these words refers to in easily accessible English terms. How best to interpret the meaning of each of these Buddhist terms, however, raises substantive philosophical issues and is not easily decided.

In the list of the five khandas, the first, rüpa, is often understood as referring simply to the physical matter of the body. Understood in this way, the physicality of the body would seem to fall outside of the psychological realm. In the Pāli dialogues, however, this term is used to connote not only the body's solidity and extension, but also its mobility, temperature regulation, fluid and digestive systems, as well as its processes of decay. For this reason, textual scholars such as Sue Hamilton have suggested that rüpa is better understood as referring to the "lived body rather than simply its flesh" (Hamilton 2000, 29). On this reading, the conceptual framework of the five khandas anticipates a number of recent proposals on which the tight coupling between body and brain constitutes an organism as a functional unity and underwrites emotion, cognition, and consciousness (Parvizi and Damasio 2001; Craig 2002). On such empirical grounds a strong argument has also been mounted that psychological processes are fundamentally grounded on life-regulation processes of the body interacting dynamically with its environment (Thompson 2007; see also Colombetti and Thompson 2008; Cosmelli and Thompson 2009).

Bodily changes such as the contraction of the gut in fear or the flush of blood in anger are an important aspect of emotional responses. Indeed, William James (1884) proposed that emotions essentially are such bodily reactions, an idea that still plays an important role in emotion theory today; for example, neuroscientist Antonio Damasio (2000) and philosopher Jesse Prinz (2004) have both argued that emotions are constituted in part by bodily reactions. But emotion theorists also recognize a second aspect of emotion, one that takes us from rūpa construed as the living body to vedana, the second of the five khandas in the Buddhist model of the mind. This second aspect is the feeling tone proper to an emotion. Some emotions feel pleasant and others feel unpleasant. 
When we consciously feel joyful, the experience is pleasant, and when we feel fearful, the experience is unpleasant. Psychologists call this aspect of emotion its affective valence or hedonic tone (see Colombetti 2005 for the complicated history behind this concept of "valence").

The notion of affect valence provides a close analogue to the Buddhist notion of vedanā. In the Khajjaniya Sutta (SN.III.86-7), vedanā is defined as feeling pleasure, feeling pain, or feeling neither-pleasure-nor-pain. In the case of both concepts, valence and vedan $\bar{a}$, the feeling tone of pleasant versus unpleasant versus neutral is closely related to action tendencies of approach versus avoidance. From the modern neuroscience perspective, the bodily responses constitutive of an emotion, including an emotion's valence and action tendency, can be activated even when we do not report consciously feeling the emotion (LeDoux 2000). For example, we may exhibit bodily responses associated with fear, even though we do not report seeing anything fearsome or feeling fearful. Such implicit emotional responses can serve to reinforce or inhibit behaviors leading to pleasant or unpleasant states, and thus influence decision-making. Thus, like vedan $\bar{a}$, valence motivates us at implicit as well as explicit levels, and influences our decisions about mundane matters, such as how much soda-pop to drink or what brand of mobile phone to buy, as well as our decisions about more profound moral choices (Loewenstein and Lerner 2003; Rozin 2003).

In understanding the function of meditative training in bringing about personal transformation, the habits of mind that dispose an individual to perceive and react to the world in certain distinctive ways are of obvious importance. These habits of mind fall under the third of the five aggregates, saimkhära. Most broadly, this category can be understood as comprising all volitional activities. These include volitions that lead to outward action - the type of volition we normally think of as the will. But they also include more internal processes, such as attention, manasikära, literally "making-in-the-mind." Thus we can understand saimkhära as referring to implicit and habitual processing routines that shape how we perceive and behave, and that typically escape explicit, cognitive awareness.

Importantly, these habits of mind not only shape our inner and outer actions, but are themselves formed through the repetition of certain kinds of inner and outer volitional activities. Thus, in addition to conditioning the other four aggregates, the samkhäras involve dynamic self-reference and self-conditioning: habits are formed and conditioned by habits (SN.III.22). ${ }^{2}$ This conception parallels recent models of cognitive events as self-forming processes arising from nonlinear interactions between components at neural and motor levels (for a review, see Cosmelli, Lachaux, and Thompson 2007). Complex (nonlinear) dynamical systems have a feature known as sensitive dependence on initial conditions: a minute change in conditions at one point in time can greatly shift the trajectory of the system down the line. Similarly, the dynamic self-formation of the samkhäras allows for the possibility of radical transformation of one's 
personality traits. In the particular case of mindfulness meditation, the suggestion is that by intentionally attending to present experience instead of dwelling in reactivity to the remembered past or the imagined future, we can radically transform the habits of attention that surface at moments of feeling threatened or tempted, and thereby transform the way we react outwardly to such situations.

Within this category of habits of mind, the role of attention is of particular interest for our purposes in this chapter. In the Mahähatthipadopama Sutta of the Majjhima Nikāya, for example, we find the following claim:

If the internal eye-organ is intact, but an external form does not come into its range... If the internal eye-organ is intact, and an external form does comes into its range, but there is not the bringing together born from that (tajja samannāhära), there is not the appearance of a degree of consciousness born from that (tajja viññanabhāga). But when the internal eye-organ is intact, and an external form does come into its range, and there is the bringing together born from that, there is the appearance of a degree of consciousness born from that.

(MN.28)

Despite other Pāli texts that omit the factor of "bringing together," samannāhāra, in the account of perceptual processes, this factor is clearly crucial in the above formulation: an external form coming into the range of an intact eye is said to result in a share or degree of consciousness only with the addition of this factor of bringing together. The traditional Pāli commentary glosses samannāhāra as here meaning manasikāra (attention). ${ }^{3}$ As the above formulation suggests, manasikāra is understood in this theoretical framework as a universal kind of attention necessary for any moment of consciousness (see also Bodhi 2000, 81). It may therefore correspond in a rough way with the basic kind of alertness required for consciousness that Parvizi and Damasio (2001) hypothesize to be dependent on subcortical structures such as the thalamus and brainstem, and that occurs independently of the direction of this consciousness to particular objects through selective attention.

This core level of consciousness, which we discuss briefly below, stands in contrast to the more cognitive functions that allow one to identify, recall, and report what one experiences. These cognitive processes are the function of the fourth aggregate, sañ $\tilde{n} \bar{a}$. In the Khajjaniya Sutta, sañ $\tilde{n} \bar{a}$ is defined as cognizing (sañjānāti) that there is blue, that there is red, yellow, or white. The term sañ $\tilde{n} \bar{a}$ is often glossed as "perception," but this interpretation is inadequate. As the Pāli scholar Peter Harvey explains, sañ $\tilde{n} \bar{a}$

is only one part of the perceptual process and...one can have a sañ $\tilde{n} \bar{a}$ of a mental object but cannot, in English, be said to "perceive" such an object... 
[T]he word "saññā" and its verbal form "sañ-jānāti" clearly refer to some kind of knowledge or knowing which is done in an associative, connective, linking (sa-) way.

(Harvey 1995, 141)

The Pāli texts contain some intriguing statements that suggest sañ $\tilde{a}$ may be akin to what philosopher Ned Block (2007, 2008) calls "cognitive access," defined as the ability to recall, report, and deliberate on a perceptual event. In the Nibbedhika Sutta (AN.VI.63), for instance, the Buddha defines sañ $\tilde{n} \bar{a}$ as that which results in spoken communication (vohāra): "As one identifies (sañjānāti) it, so one says 'I saw thus.'

Sa $\tilde{n} \tilde{n} \bar{a}$ is differentiated in the Buddhist model of the mind from viñ $\tilde{n} \bar{n} n a$, the fifth aggregate, often glossed as "consciousness." It is tempting to relate this notion to what Block calls "phenomenal consciousness" (Block 1995, $2007,2008)$. Whereas phenomenal consciousness consists in "what it is like" for a subject to have or undergo an experience, cognitive access consists in having the content of an experience enter working memory so that one can identify and report on this content. Given this distinction, viñ $\tilde{a} \bar{a} n a$, defined as a moment of either visual, auditory, tactile, olfactory, gustatory, or mental awareness, would be analogous to phenomenal consciousness, whereas sañ $\tilde{n} \bar{a}$, defined as a recognitional ability, would be analogous to cognitive access.

Yet this tentative analogy between Pāli Buddhist and cognitive science conceptions of consciousness needs refinement. Block conceives of phenomenal consciousness as a state of experiencing in a rich and vivid way certain objects or properties, for instance a state of seeing red. Without such a notion of phenomenally conscious states as essentially including modality-specific content, it would make little sense to suggest, as Block does, that phenomenal consciousness might be realized by certain patterns of recurrent neural activity in visual areas of the brain (Block 2005). In contrast, recall Parvizi and Damasio's suggestion that there is a basic, core level of consciousness, dependent on the thalamus and brainstem, that occurs independently of selective attentional processes in higher cortical areas (Parvizi and Damasio 2001). This core or ground floor level of consciousness depends on a basic kind of alerting function distinct from the higher-level mechanisms of selective attention that come into play in determining what one is conscious of. On this view, the fact that there is a phenomenal feel - the fact that there is something it is like for a subject - depends on the basic alerting function. In contrast, the content of phenomenal consciousness - what it is like for a subject - depends also on how this consciousness is directed to particular objects and properties through selective attention. Put another way, the particular contents of phenomenal consciousness can be seen as modifications or modulations of a basal level of awareness dependent on the alerting function (see also Searle 2000). 
We suggested above that the Pāli Buddhist concept of manasikāra may be analogous to this alerting function, rather than to selective attention. Correspondingly, viñ̃̃ana may be best understood from this cognitive science perspective as analogous to a basal level of awareness common to all phenomenally conscious states.

We need to be cautious, however, in drawing any of the foregoing parallels between the fourth and fifth aggregates and cognitive science conceptions of cognitive access and consciousness. Currently there is no consensus in cognitive science about whether phenomenal consciousness and cognitive access are two different phenomena, or whether phenomenal consciousness depends constitutively on cognitive access. ${ }^{4}$ On the one hand, it seems odd to say that you can have a conscious experience that you do not know you are having. And if knowing that you are having a certain experience, such as a visual experience of the color red or a tactile experience of hardness, requires the cognitive functions of identifying the object or properties being experienced, then it seems problematic to postulate a type of experience that occurs independent of cognitive access. Furthermore, given that the principal scientific criterion for the presence of consciousness is behavioral report, and behavioral report requires cognitive access, how could such a subjective experience ever be investigated?

On the other hand, it seems unsatisfactory to assume, in advance of the evidence, that having a conscious experience consists wholly in various cognitive operations such as identifying its content or identifying oneself as having experienced that content. Proponents of drawing a distinction between phenomenal consciousness and cognitive access need only posit that some instances of phenomenal consciousness happen not to be cognitively accessed; they need not posit that there are subjective experiences that the subject cannot access or know about. Indeed, one function of phenomenal consciousness may be to make its content accessible for encoding in working memory, for the purposes of identification, recall, deliberation, and report (Prinz 2005). Certain experiences may be too fleeting and rapid to stabilize in working memory, as various kinds of evidence have sometimes been taken to suggest (see Kouider et al. 2010; Block 2011). Nevertheless, such experiences may not be inaccessible in principle; for instance, it may be possible to gain greater cognitive access to them through the kind of mental training central to mindfulness meditation.

We believe this last point indicates a major shortcoming in the current debates about consciousness within cognitive science. These debates have proceeded without significant consideration given to the possibility that specific forms of mental training, such as mindfulness meditation practices, might be able to produce new data about the relationship between attention and consciousness. Here is an area where Buddhist theory has much to contribute to cognitive science. We take up this topic in the next section. 


\section{Attention and Consciousness}

Attention and consciousness seem to be tightly interlinked in normal subjects in everyday conditions of perception. Therefore, empirical research has focused on subjects in conditions outside the normal range in order to test whether consciousness can occur in the absence of attention, and whether attention can occur without consciousness. Yet little agreement exists on what the research to-date shows. Does it confirm the commonsense idea that we must be conscious of something in order to attend to it, as philosopher Christopher Mole $(2008,2011)$ contends? Or is it rather the other way round, that attention is a prerequisite for consciousness, as neuroscientist Stanislave Dehaene and his colleagues have argued (Dehaene et al. 2006)? Or is attention both necessary and sufficient for consciousness, as philosopher Jesse Prinz (2011) maintains? Alternatively, are attention and consciousness doubly dissociable, such that there can be attention without consciousness and consciousness without attention, as neuroscientists Christof Koch and Naotsugu Tsuchiya (2007) propose? In these debates, cognitive scientists have appealed to studies on various kinds of alterations or disruptions to normal visual consciousness, such as occur in binocular rivalry, blindsight, and the so-called attentional blink. As we now discuss, in each of these cases, studies of meditation may offer important additional information relevant to the ongoing debates.

In normal vision, the brain receives visual images from each eye that present slightly differing perspectives on the same scene. In the paradigm known as binocular rivalry, however, each eye is presented with a different image at the same time. For example, one eye may receive the image of a house while the other eye receives the image of a face. Subjects generally report seeing one image at a time but also that their perception switches unpredictably between the two images. Two kinds of results from empirical studies of binocular rivalry are relevant for our purposes here. On the one hand, the visual image that is not consciously seen provokes significant neural responses selective to its particular features. For example, the image of a fearful face has been found to activate the amygdala, an area of the brain associated with perceiving emotionally salient stimuli (Williams et al. 2004). On the other hand, voluntary shifts in attention have been shown to affect which image becomes consciously seen (Ooi and He 1999). Moreover, in an intriguing study, Olivia Carter and her colleagues found that long-term Tibetan Buddhist practitioners of concentration meditation were able to change the perceptual switching rate when they viewed the images while practicing this type of meditation (with eyes open focused on the display as the meditative object) (Carter et al. 2005). A large number of the practitioners reported that the amount of time one image remained perceptually dominant increased considerably while practicing concentration meditation as well as immediately after meditation. 
Three individuals reported that the image remained completely stable with no switching for an entire five-minute period of concentration meditation. In some cases, one of the two images was completely dominant; in other cases, the non-dominant image remained faintly or partially visible behind the dominant one, so that the conscious perception was of two superimposed images. As Carter and her colleagues observe, "These results contrast sharply with the reported observations of over 1000 meditation-naïve individuals tested previously." Thus, it may be that meditative training of voluntary attention enables long-term practitioners of concentration meditation to stabilize consciousness of one or the other image in a way that normal subjects are unable to do.

In an important review article, Lutz and colleagues suggest that, in addition to the top-down orienting network, which voluntarily allocates selective attention to a chosen object, concentration or "focused attention" styles of meditation involve a "monitoring" function necessary to detect when attention has wandered away from the chosen object (Lutz et al. 2008). Lutz and colleagues distinguish such "focused attention" practices from "open monitoring" practices, which may involve focused attention training at early stages of practice, but use the development of the monitoring skill to be able eventually to drop any intentional selection or deselection within the field of present experience. Instead, in open monitoring styles of practice, meditators aim to remain attentive to whatever arises in moment-to-moment experience, without becoming lost in mind-wandering. Open monitoring styles of meditation include certain Tibetan Buddhist and Chan/Zen practices, as well as mindfulness meditation derived from Theravāda Buddhist sources. According to traditional descriptions, at advanced stages of this style of practice the attentiveness to whatever arises continues without the effortful and relatively slow process of selection and deselection, so that the practice becomes agile and effortless.

In this connection, a recent neuroimaging study offers suggestive results (Manna et al. 2010). Antonietta Manna and her colleagues used functional magnetic resonance imaging (fMRI) to monitor Theravāda Buddhist monks expert in both concentration and mindfulness practices, as contrasted to a group of lay novice practitioners. In the expert meditators, the brain activity patterns in open monitoring meditation resembled those of the resting state, whereas the activity patterns in both of these states contrasted sharply with those in focused attention meditation on the breath. Manna and colleagues interpret this finding as suggesting that "open monitoring ('mindfulness') is also reflected and thus practiced in ordinary non-meditative conditions" (Manna et al. 2010, 52).

This result suggests another proposal for the meaning of mindfulness (as discussed above), seen especially in relation to cognitive science issues about the relationship between attention and consciousness. We noted above that in the Pāli Buddhist framework a basic and universal kind of attention, manasikāra, is held to be necessary for consciousness. The scholar-practitioner Anālayo 
suggests that sati "can be understood as a further development and temporal extension of this type of attention [manasikära], thereby adding clarity and depth to the usually too short fraction of time occupied by bare attention in the perceptual process" (Anālayo 2004, 59). Whereas the focusing of attention in concentration practices involves activation of top-down orienting networks, mindfulness practice may consist in enhancing the processes involved in sustaining alert consciousness more generally. If this were the case, then we should expect that long-term, trait increases in one's consciousness of subtle stimuli (as opposed to transitory state increases) would be evident even in resting states.

Scientists who argue that distinct neural systems subserve selective attention and consciousness (e.g., Koch and Tsuchiya 2007) also appeal to pathological cases, in particular a condition known as blindsight. As a result of damage to the visual cortex, patients in this condition report having no visual experience in affected areas of the visual field, but they can nonetheless detect and discriminate features of the presented stimuli that they deny seeing. Kentridge, Heywood, and Weiskrantz (1999) found that in one blindsight patient, topdown attention could be cued so as to increase detection and discrimination of stimuli that were not consciously seen, even when the cue itself was not consciously experienced. Corbetta and Schulman (2002) suggest that damage to neural systems involved in stimulus-driven alerting is responsible for this condition, while orienting systems remain intact. This hypothesis is consistent with the suggestion that a basic kind of alerting is necessary for phenomenal consciousness, whereas top-down orienting is not. Yet because brain damage can have unknown, non-specific effects, it is difficult to generalize from findings in pathological populations to claims about attention and consciousness in normal populations. In order to triangulate more precisely which functions are inhibited in pathological conditions such as blindsight, it may be helpful to have evidence from the other end of the spectrum, that is, from a pool of individuals with attentional abilities significantly greater than normal. Experienced Buddhist meditators may provide such a pool.

Earlier, when discussing the five aggregate model of the mind, we noted that in order to be able to recall and report on events, one needs to have identified them at the time they occurred: "As one identifies (sañjānäti) it, so one says 'I saw thus' " (A.VI.63). Attentiveness plays a role here, too. For example, studies of the so-called "attentional blink" require that one identify two visual targets (such as letters, words, or images) presented within 200-500 milliseconds of each other in a rapid sequence of other distracting visual stimuli. Subjects often notice the first target but fail to notice the second one. The standard explanation is that detecting the first target uses up the available attentional resources, so the second target is missed and not reported. A recent study showed that the ability to detect the second target was greatly improved after a three-month intensive mindfulness meditation retreat, and that this 
improvement correlated with EEG measures showing more efficient neural responses to the first target (Slagter et al. 2007). Importantly, the participants were instructed not to meditate during the task, so the improved performance indicates that mindfulness meditation has lasting effects on attention outside of the context of meditation practice. The authors of this study suggest that mindfulness meditation may lead to less elaborative cognitive processing of the first visual target - less "mental stickiness" to it - and that this reduction facilitates the ability to identify and report the second rapidly occurring target.

Support for this suggestion comes from recent work on mind-wandering and its association with the brain's so-called default mode network. The default mode network comprises a set of brain regions active in the resting state but whose activity decreases during externally directed and attention-demanding perceptual tasks (Buckner, Andrews-Hanna, and Schacter 2008); these regions have also been shown to be active during mind-wandering (Mason et al. 2007; Christoff et al. 2009), including mind-wandering during focused attention meditation conditions (Hasenkamp et al. 2012). Training in mindfulness meditation is associated with decreases in default mode network activation (Brewer et al. 2011; Berkovich-Ohana, Glicksohn, and Goldstein 2012) and with corresponding increased activation in visceral and somatic areas associated with interoception (Farb et al. 2007, 2010; Farb, Segal, and Anderson 2013b).

Such decreases in elaborative thought and corresponding increases in interoceptive awareness are relevant to understanding the role of mindfulness practice in increased emotional awareness. In a recent study, mindfulness meditators showed significantly more coherence between physiological changes and their subjective awareness of emotional responses than did either professional dancers (ballet and modern dance), or control subjects with no meditation or dance experience (Sze et al. 2010). Mindfulness meditators were more aware of their visceral responses and thereby more aware of their emotions. In another study, Silverstein et al. (2011) report evidence of increased interoceptive awareness in female undergraduates engaged in mindfulness training. These authors suggest that women who were distracted by emotionally driven self-evaluative thoughts were much slower in registering their bodily reactions, as measured by reaction time in rating physiological response to sexual stimuli, whereas mindfulness meditation training increased awareness of bodily reactions by decreasing self-evaluative thoughts. Finally, in another study, although both experienced and beginning mindfulness meditators reported that the emotional intensity of positively and negatively valenced pictures was attenuated during mindfulness practice, the attenuation was associated with different brain activity patterns in the two groups (Taylor et al. 2011). Whereas the experienced meditators showed decreased default mode network activity without a corresponding decrease in brain areas associated with emotional reactivity, the beginning meditators showed no decrease in default mode network activity but rather a decrease in the left amygdala, 
a brain area associated with reactivity to emotionally salient stimuli. While increased emotion regulation in beginning meditators may depend partly on changes in how they think about the situations encountered, the attenuated subjective experience of emotional reactions in advanced practitioners seems to be related instead to a decrease in elaborative thought. One possible interpretation of these results is to suggest that it is precisely in virtue of being more aware of their own emotional reactions that advanced mindfulness practitioners are able to disrupt habitual emotional reactivity, and thus attenuate the subjective intensity of emotional response to pleasant or unpleasant situations.

\section{Conclusion}

As we have seen, the establishment of mindfulness begins by relying on working memory in order to maintain an attentional set for orienting voluntary, selective attention to a given object, such as the present sensations of breathing. One effect of this practice is to enable increased cognitive access by facilitating identification of what is observed, as well as later recall and report. Eventually, however, it is the reduction in elaborative cognitive processing - in thoughts about the imagined past or mentally projected future, especially self-related thoughts - that allows for increased phenomenal consciousness of current stimuli. According to this conception, mindfulness can be seen as a developed form of the basic alerting mechanisms necessary for any moment of consciousness, rather than as a function of top-down orienting or of cognitive access.

Understanding mindfulness as a strategy of decreasing elaborative thought and enhancing phenomenal awareness helps to distinguish it from more cognitive strategies, such as changing how one thinks about the challenging or distressing situations one encounters in daily life. Such cognitive strategies are widespread in clinical psychology, and they have influenced how the practice of mindfulness has been received. One example is a recent trend in clinical psychology toward emphasizing the ability of mindfulness to facilitate specifically positive reappraisal. For instance, Garland and colleagues give the example of mindfulness allowing individuals to reappraise a serious heart condition as "an opportunity to change their lifestyle and health behaviors rather than as a catastrophe portending imminent doom" (Garland, Gaylord, and Fredrickson 2011, 60). We believe, however, that the tendency to assimilate mindfulness meditation to this type of intervention carries the risk of missing its radical promise.

Buddhist teachings do include many types of cognitive reflections; we noted above the practice of remembering or reflecting on death (maranasati). As the Pāli term for this practice indicates, such reflections require sati, in the 
sense of attentiveness. In light of the analysis offered above, however, we can draw a sharp distinction between such practices of reflection and mindfulness meditation (satipatthāna). In reflection practices, working memory functions to maintain in mind thoughts with a particular content, for instance about the inevitability of one's death, and thereby engender a certain type of emotional response. Working memory also plays an important role in concentration, by maintaining an attentional set for orienting to a particular meditation object. In the context of mindfulness meditation, however, we have suggested that the function of such orienting is to reduce elaborative cognitive processing and thereby allow for increased phenomenal consciousness of current stimuli.

Moreover, traditional Buddhist presentations do not support a conception of mindfulness as biasing subjects specifically toward positive appraisal of life situations. We have seen that on both Buddhist and empirical models, organisms respond to the constant flow of pleasant and unpleasant valence, vedan $\bar{a}$, with habitual reactive routines of craving and aversion. In the Buddhist context, latent craving and aversion are said to result in perceptual distortions

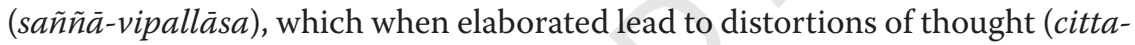
vipalläsa) and, when such thought patterns become habitual, to distortions of view (ditthi-vipallāsa) (see e.g. the translator's introduction to Olendzki 2010). This Buddhist viewpoint finds a parallel in the empirical context, where affective bias is taken as underlying emotional distortions of attention and memory (Elliott et al. 2010). Thus the role of mindfulness meditation in dispelling emotional distortions may rest on its ability to attenuate both positive and negative affective biases.

These points suggest two ways in which mindfulness may achieve the traditional goal of "seeing things as they are" ( yathäbhütañanadassana). One function of mindfulness is to counteract not knowing. Under normal circumstances we miss much of what is going on. By increasing phenomenal consciousness of subtle changes in our bodies and in our environments, we may make this information available to be encoded in working memory and thus to be identified, deliberated on, and expressed to others. A second function of mindfulness is to counteract knowing wrongly. Through attenuating affective bias, we can gradually replace emotionally distorted perceptions, thoughts, and views with undistorted cognitions. These two functions of mindfulness are mutually reinforcing. Accordingly, we can understand Buddhist teachings as claiming that our normal modes of mind-wandering involve the proliferation of distorting emotional reactivity, but that we can attenuate the affective biases on which this reactivity depends by sustaining a bare and lucid phenomenal consciousness of present stimuli. If so, one of the most interesting questions for future research will be to address in psychological and neural terms exactly how this transformative mechanism works. 


\section{Notes}

1 The term satipatthāna has commonly been rendered as a (plural) noun, the (four) "foundations of mindfulness." But the primary sense of the term is verbal and refers to the active practice of establishing mindfulness, as noted recently by prominent translators such as Bhikkhu Bodhi (2011) and Thanissaro Bhikkhu (see the translator's introduction to Thanissaro Bhikkhu 2011). For a critique of the more standard gloss of satipatthāna as "foundations of mindfulness" and the commentarial derivation of the term from patthāna on which this gloss is based, see Anālayo (2004, 29-30).

2 SN.III.22, "san்khäre san்khärattāya san்khatamabhisan்kharonti."

$3 \mathrm{MN}$-a.II.229. This interpretation is confirmed by the use of these terms as synonyms in the suttas, as at MN.65 (Harvey 1995, 129-130).

4 For a sampling of the debate, see Lamme (2003), Block (2005, 2011), Kouider et al. (2010), and Cohen and Dennett (2011).

\section{References}

Anālayo. 2004. Satipațthāna: The Direct Path to Realization. Cambridge: Windhorse Publications.

Berkovich-Ohana, A., Glicksohn, J., and Goldstein, A. 2012. "MindfulnessInduced Changes in Gamma Band Activity: Implications for the Default Mode Network, Self-Reference and Attention." Clinical Neurophysiology 123(4): 700-710. doi:10.1016/j.clinph.2011.07.048

Bishop, S.R., Lau, M., Shapiro, S., Carlson, L., Anderson, N.D., Carmody, J., et al. 2004. "Mindfulness: A Proposed Operational Definition." Clinical Psychology: Science and Practice 11(3): 230-241. doi:10.1093/clipsy.bph077

Block, N. 1995. "On a Confusion About a Function of Consciousness." Behavioral and Brain Sciences 18: 227-247.

Block, N. 2005. "Two Neural Correlates of Consciousness." Trends in Cognitive Sciences 9(2): 46-52. doi:10.1016/j.tics.2004.12.006

Block, N. 2007. "Consciousness, Accessibility, and the Mesh Between Psychology and Neuroscience." Behavioral and Brain Sciences 30(5-6): 481-548. doi:10.1017/S0140525X07002786

Block, N. 2008. "Consciousness and Cognitive Access." Proceedings of the Aristotelian Society (Hardback) 108(1pt3): 289-317. doi:10.1111/j.1467-9264.2008.00247.x

Block, N. 2011. "Perceptual Consciousness Overflows Cognitive Access." Trends in Cognitive Sciences 15(12): 567-575. doi:10.1016/j.tics.2011.11.001 Bodhi, Bhikkhu, ed. 2000. A Comprehensive Manual of Abhidhamma. 1st BPS Pariyatti edition. Seattle: Pariyatti Publishing. 
Bodhi, Bhikkhu. 2011. "What Does Mindfulness Really Mean? A Canonical Perspective." Contemporary Buddhism 12(1): 19-39. doi:10.1080/14639947. 2011.564813

Brewer, J.A., Worhunsky, P.D., Gray, J.R., Tang, Y.-Y., Weber, J., and Kober, H. 2011. "Meditation Experience is Associated with Differences in Default Mode Network Activity and Connectivity." Proceedings of the National Academy of Sciences 108(50): 20254-20259. doi:10.1073/pnas.1112029108

Buckner, R.L., Andrews-Hanna, J.R., and Schacter, D.L. 2008. “The Brain's Default Network." Annals of the New York Academy of Sciences 1124(1): 1-38. doi:10.1196/annals.1440.011

Carter, O.L., Presti, D.E., Callistemon, C., Ungerer, Y., Liu, G.B., and Pettigrew, J.D. 2005. "Meditation Alters Perceptual Rivalry in Tibetan Buddhist Monks." Current Biology 15(11): R412-R413.

Christoff, K., Gordon, A.M., Smallwood, J., Smith, R., and Schooler, J.W. 2009. "Experience Sampling During fMRI Reveals Default Network and Executive System Contributions to Mind Wandering." Proceedings of the National Academy of Sciences 106(21): 8719.

Cohen, M.A. and Dennett, D.C. 2011. "Consciousness Cannot Be Separated from Function." Trends in Cognitive Sciences 15(8): 358-364. doi:10.1016/ j.tics.2011.06.008

Colombetti, G. 2005. “Appraising Valence." Journal of Consciousness Studies 12(8-10): 103-126.

Colombetti, G. and Thompson, E. 2008. "The Feeling Body: Toward an Enactive Approach to Emotion." In Body in Mind, Mind in Body: Developmental Perspectives on Embodiment and Consciousness, edited by W.F. Overton, U. Muelle, and J. Newman, 45-68. Mahwah: Erlbaum.

Corbetta, M. and Shulman, G.L. 2002. "Control of Goal-Directed and StimulusDriven Attention in the Brain." Nature Reviews Neuroscience 3(3): 201-215.

Cosmelli, D. and Thompson, E. 2009. "Embodiment or Envatment? Reflections on the Bodily Basis of Consciousness." In Enaction: Towards a New Paradigm for Cognitive Science, edited by J. Stewart, O. Gapenne, and E.A. Di Paolo. Cambridge, MA: The MIT Press.

Cosmelli, D., Lachaux, J.P., and Thompson, E. 2007. "Neurodynamical Approaches to Consciousness." In The Cambridge Handbook of Consciousness, edited by P.D. Zelazo, M. Moscovitch, and E. Thompson. Cambridge, UK: Cambridge University Press.

Craig, A.D. 2002. "How Do You Feel? Interoception: The Sense of the Physiological Condition of the Body." Nature Reviews Neuroscience 3(8): 655. doi:10.1038/nrn894

Damasio, A.R. 2000. The Feeling of What Happens: Body and Emotion in the Making of Consciousness. New York: Mariner Books.

Davidson, R.J. 2010. "Empirical Explorations of Mindfulness: Conceptual and Methodological Conundrums." Emotion 10(1): 8-11. 
De Fockert, J.W., Rees, G., Frith, C.D., and Lavie, N. 2001. "The Role of Working Memory in Visual Selective Attention.” Science 291(5509): 1803-1806. doi:10.1126/science.1056496

Dehaene, S., Changeux, J., Naccache, L., Sackur, J., and Sergent, C. 2006. "Conscious, Preconscious, and Subliminal Processing: A Testable Taxonomy." Trends in Cognitive Sciences 10(5): 204-211. doi:10.1016/j.tics.2006.03.007

Desimone, R. and Duncan, J. 1995. "Neural Mechanisms of Selective Visual Attention." Annual Review of Neuroscience 18(1): 193-222.

Dreyfus, G. 2011. "Is Mindfulness Present-Centred and Non-judgmental? A Discussion of the Cognitive Dimensions of Mindfulness." Contemporary Buddhism 12(1): 41-54. doi:10.1080/14639947.2011.564815

Elliott, R., Zahn, R., Deakin, J.F.W., and Anderson, I.M. 2010. "Affective Cognition and Its Disruption in Mood Disorders." Neuropsychopharmacology 36(1): 153. doi:10.1038/npp.2010.77

Farb, N.A.S., Segal, Z.V., Mayberg, H., Bean, J., McKeon, D., Fatima, Z., and Anderson, A.K. 2007. "Attending to the Present: Mindfulness Meditation Reveals Distinct Neural Modes of Self-Reference." Social Cognitive and Affective Neuroscience 2(4): 313.

Farb, N.A.S., Anderson, A.K., Mayberg, H., Bean, J., McKeon, D., and Segal, Z.V. 2010. "Minding One's Emotions: Mindfulness Training Alters the Neural Expression of Sadness." Emotion 10(1): 25-33.

Farb, N.A.S., Segal, Z.V., and Anderson, A.K. 2013a. "Attentional Modulation of Primary Interoceptive and Exteroceptive Cortices." Cerebral Cortex 23(1): 114-126.

Farb, N.A.S., Segal, Z.V., and Anderson, A.K. 2013b. "Mindfulness Meditation Training Alters Cortical Representations of Interoceptive Attention." Social Cognitive and Affective Neuroscience 8(1): 15-26.

Garland, E.L., Gaylord, S.A., and Fredrickson, B.L. 2011. "Positive Reappraisal Mediates the Stress-Reductive Effects of Mindfulness: An Upward Spiral Process." Mindfulness 2(1): 59-67. doi:10.1007/s12671-011-0043-8

Gethin, R. 2011. "On Some Definitions of Mindfulness." Contemporary Buddhism 12(1): 263-279. doi:10.1080/14639947.2011.564843

Grossman, P., Tiefenthaler-Gilmer, U., Raysz, A., and Kesper, U. 2007. "Mindfulness Training as an Intervention for Fibromyalgia: Evidence of Postintervention and 3-Year Follow-Up Benefits in Well-Being." Psychotherapy and Psychosomatics 76(4): 226-233. doi:10.1159/000101501

Hamilton, S. 2000. Early Buddhism: A New Approach: The I of the Beholder. Richmond, Surrey: Curzon Press.

Harvey, P. 1995. The Selfless Mind: Personality, Consciousness and Nirvana in Early Buddhism. Reissue. London: Routledge.

Hasenkamp, W., Wilson-Mendenhall, C.D., Duncan, E., and Barsalou, L.W. 2012. "Mind Wandering and Attention During Focused Meditation: A FineGrained Temporal Analysis of Fluctuating Cognitive States." NeuroImage 59(1): 750-760. doi:10.1016/j.neuroimage.2011.07.008 
Hölzel, B.K., Carmody, J., Vangel, M., Congleton, C., Yerramsetti, S.M., Gard, T., and Lazar, S.W. 2011a. "Mindfulness Practice Leads to Increases in Regional Brain Gray Matter Density." Psychiatry Research 191(1): 36-43. doi:10.1016/ j.pscychresns.2010.08.006

Hölzel, B.K., Lazar, S.W., Gard, T., Schuman-Olivier, Z., Vago, D.R., and Ott, U. 2011b. "How Does Mindfulness Meditation Work? Proposing Mechanisms of Action From a Conceptual and Neural Perspective." Perspectives on Psychological Science 6(6): 537-559. doi:10.1177/1745691611419671 James, W. 1884. “What is an Emotion?” Mind 9(34): 188-205.

Jha, A.P., Krompinger, J., and Baime, M.J. 2007. "Mindfulness Training Modifies Subsystems of Attention." Cognitive, Affective, \& Behavioral Neuroscience 7(2): 109-119.

Kabat-Zinn, J. 2004. Wherever You Go, There You Are. New York: Hyperion.

Kabat-Zinn, J. 2011. "Some Reflections on the Origins of MBSR, Skillful Means, and the Trouble with Maps." Contemporary Buddhism 12(1): 281-306. doi:10.1080/14639947.2011.564844

Kentridge, R.W., Heywood, C.A., and Weiskrantz, L. 1999. "Attention Without Awareness in Blindsight." Proceedings of the Royal Society of London. Series B: Biological Sciences 266(1430): 1805-1811. doi:10.1098/rspb. 1999.0850

Koch, C. and Tsuchiya, N. 2007. "Attention and Consciousness: Two Distinct Brain Processes.” Trends in Cognitive Sciences 11(1): 16-22.

Kouider, S., Gardelle, V. de, Sackur, J., and Dupoux, E. 2010. "How Rich is Consciousness? The Partial Awareness Hypothesis." Trends in Cognitive Sciences 14.(7): 301-307. doi:10.1016/j.tics.2010.04.006

Lamme, V.A.F. 2003. "Why Visual Attention and Awareness are Different." Trends in Cognitive Sciences 7(1): 12-18.

LeDoux, J.E. 2000. "Emotion Circuits in the Brain." Annual Review of Neuroscience 23: 155-184.

Loewenstein, G. and Lerner, J.S. 2003. "The Role of Affect in Decision Making." In Handbook of Affective Sciences, edited by R.J. Davidson, K.R. Scherer, and H.H. Goldsmith. New York: Oxford University Press.

Lutz, Antoine, Dunne, J.D., and Davidson, R.J. 2007. "Meditation and the Neuroscience of Consciousness." In The Cambridge Handbook of Consciousness, edited by P.D. Zelazo, M. Moscovitch, and E. Thompson. Cambridge, UK: Cambridge University Press.

Lutz, A., Slagter, H.A., Dunne, J.D., and Davidson, R.J. 2008. "Attention Regulation and Monitoring in Meditation." Trends in Cognitive Sciences 12(4): 163-169. doi:10.1016/j.tics.2008.01.005

Manna, A., Raffone, A., Perrucci, M.G., Nardo, D., Ferretti, A., Tartaro, A., et al. 2010. "Neural Correlates of Focused Attention and Cognitive Monitoring in Meditation." Brain Research Bulletin 82(1-2): 46-56. doi:10.1016/j. brainresbull.2010.03.001 
Mason, M.F., Norton, M.I., Van Horn, J.D., Wegner, D.M., Grafton, S.T., and Macrae, C.N. 2007. "Wandering Minds: The Default Network and StimulusIndependent Thought." Science 315(5810): 393-395. doi:10.1126/ science. 1131295

Mole, C. 2008. "Attention and Consciousness." Journal of Consciousness Studies 15(4): 86-104.

Mole, C. 2011. Attention is Cognitive Unison: An Essay in Philosophical Psychology. New York: Oxford University Press.

Olendzki, A., trans. 2010. "Vipallasa Sutta: Distortions of the Mind." Access to Insight. www.accesstoinsight.org/tipitaka/an/an04/an04.049.olen.html

Ooi, T.L. and He, Z.J. 1999. "Binocular Rivalry and Visual Awareness: The Role of Attention." Perception 28(5): 551-574.

Parvizi, J. and Damasio, A. 2001. "Consciousness and the Brainstem." Cognition 79(1-2): 135-160.

Prinz, J.J. 2004. Gut Reactions: A Perceptual Theory of Emotion. New York: Oxford University Press.

Prinz, J.J. 2005. "A Neurofunctional Theory of Consciousness." In Cognition and the Brain: The Philosophy and Neuroscience Movement, edited by A. Brook and K. Akins, 381-396. Cambridge, UK: Cambridge University Press.

Prinz, J.J. 2011. "Is Attention Necessary and Sufficient for Consciousness?" In Attention: Philosophical and Psychological Essays, edited by C. Mole, D. Smithies, and W. Wu, 174-204. New York: Oxford University Press.

Rolls, E. 2007. Memory, Attention, and Decision-Making: A Unifying Computational Neuroscience Approach, 1st edition. New York: Oxford University Press.

Rozin, G. 2003. "Introduction: Evolutionary and Cultural Perspectives on Affect." In Handbook of Affective Sciences, edited by R.J. Davidson, K.R. Scherer, and H.H. Goldsmith. New York: Oxford University Press.

Schubert, R., Blankenburg, F., Lemm, S., Villringer, A., and Curio, G. 2006. "Now You Feel It - Now You Don't: ERP Correlates of Somatosensory Awareness." Psychophysiology 43(1): 31-40.

Schubert, R., Ritter, P., Wüstenberg, T., Preuschhof, C., Curio, G., Sommer, W., and Villringer, A. 2008. "Spatial Attention Related SEP Amplitude Modulations Covary with BOLD Signal in S1: A Simultaneous EEG-fMRI Study." Cerebral Cortex 18(11): 2686.

Schubert, R., Haufe, S., Blankenburg, F., Villringer, and Curio, G. 2009. “Now You'll Feel It, Now You Won't: EEG Rhythms Predict the Effectiveness of Perceptual Masking." Journal of Cognitive Neuroscience 21(12): 2407-2419.

Searle, J.R. 2000. “Consciousness." Annual Review of Neuroscience 23(1): 557-578. doi:10.1146/annurev.neuro.23.1.557

Silverstein, R.G., Brown, A.-C.H., Roth, H.D., and Britton, W.B. 2011. "Effects of Mindfulness Training on Body Awareness to Sexual Stimuli: Implications for Female Sexual Dysfunction." Psychosomatic Medicine 73(9): 817-825. doi:10.1097/PSY.0b013e318234e628 
Slagter, H.A., Lutz, A., Greischar, L.L., Francis, A.D., Nieuwenhuis, S., Davis, J.M., and Davidson, R.J. 2007. "Mental Training Affects Distribution of Limited Brain Resources.” PLoS Biology 5(6): e138. doi:10.1371/journal.pbio.0050138 Sze, J.A., Gyurak, A., Yuan, J.W., and Levenson, R.W. 2010. “Coherence Between Emotional Experience and Physiology: Does Body Awareness Training Have an Impact?" Emotion 10: 803-814. doi:10.1037/a0020146

Taylor, V.A., Grant, J., Daneault, V., Scavone, G., Breton, E., Roffe-Vidal, S., et al. 2011. "Impact of Mindfulness on the Neural Responses to Emotional Pictures in Experienced and Beginner Meditators." NeuroImage 57(4): 1524-1533. doi:10.1016/j.neuroimage.2011.06.001

Thanissaro Bhikkhu, trans. 2011. "Maha-satipatthana Sutta: The Great Frames of Reference." Access to Insight. www.accesstoinsight.org/tipitaka/dn/dn. 22.0.than.html

Thompson, E. 2007. Mind in Life: Biology, Phenomenology, and the Sciences of Mind. Cambridge, MA: Belknap Press.

Varela, F.J., Thompson, E., and Rosch, E. 1991. The Embodied Mind: Cognitive Science and Human Experience. Cambridge, MA: The MIT Press.

Williams, M.A., Morris, A.P., McGlone, F., Abbott, D.F., and Mattingley, J.B. 2004. "Amygdala Responses to Fearful and Happy Facial Expressions Under Conditions of Binocular Suppression." The Journal of Neuroscience 24(12): 2898-2904. doi:10.1523/JNEUROSCI.4977-03.2004 
